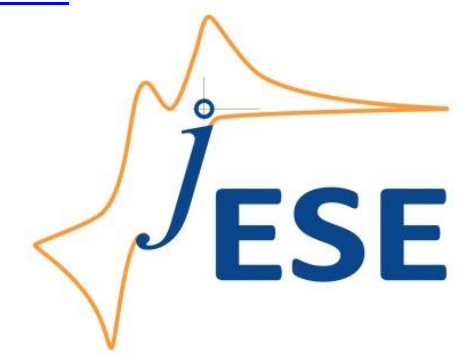

Open Access : : ISSN 1847-9286

www.jESE-online.org

Original scientific paper

\title{
Graphene based sulfonated polyvinyl alcohol hydrogel nanocomposite for flexible supercapacitors
}

\author{
Subhakaran Singh Rajaputra ${ }^{1,2}$, Nagalakshmi Pennada ${ }^{1,2}$, Anjaneyulu Yerramilli1 ${ }^{1,2}$, \\ Naga Mahesh Kummara1, ${ }^{1,}$
}

${ }^{1}$ Centre for Advanced Energy Studies, Koneru Lakshmaiah Education Foundation, Vaddeswaram, Guntur Dist. 522 502, AP, India

${ }^{2}$ Department of Chemistry, Koneru Lakshmaiah Education Foundation, Vaddeswaram, Guntur Dist.

522 502, AP, India

*Corresponding author: ${ }^{*}$ nagamaheshk@gmail.com

Received: June 22, 2021; Revised: July 22, 2021; Accepted: July 29, 2021; Published: August 3, 2021

\begin{abstract}
Graphene based sulfonated polyvinyl alcohol (PVA) hydrogel was synthesized and its performance as nanocomposite gel polymer electrolyte was investigated for application in quasi solid-state flexible supercapacitors. Hydrothermally reduced graphene (HRG) was synthesized through hydrothermal reduction of graphene oxide (GO). Sulfonated PVA hydrogel (SPVA) was synthesized with predetermined quantities of HRG to obtain nanocomposite gel polymer electrolytes coded as SPVA-HRG-x ( $x=$ content (wt.\%) of HRG). The amorphous nature of SPVA-HRG- $x$ was determined using $X$-ray diffraction (XRD) technique. The electrochemical performance of SPVA-HRG-X was evaluated using techniques like cyclic voltammetry (CV), galvanostatic charge-discharge (GCD) and electrochemical spectroscopy (EIS) studies of a lab scale supercapacitor cell, fabricated using hydrothermally reduced carbon cloth (CCHy) current collectors coated with HRG (HRG-CCHy). In SPVA-HRG-0.5 electrolyte, HRG-CCHy exhibited specific capacitance of $200 \mathrm{~F} \mathrm{~g}^{-1}$ at $1 \mathrm{~A} \mathrm{~g} \mathrm{~g}^{-1}$ and specific energy of $6.1 \mathrm{Wh} \mathrm{kg}^{-1}$ at specific power of $1 \mathrm{~kW} \mathrm{~kg}^{-1}$ and retained $93 \%$ of its initial capacitance even after 5000 GCD cycles. The incorporation of SPVA with 0.5 wt.\% of HRG-CCHy can be attributed to the increase in amorphous nature of SPVA-HRG-0.5, which in-turn lowers its impedance. This contributed to the remarkable supercapacitive behaviour of HRG-CCHy, demonstrating its potential as gel polymer electrolyte (GPE) for application in quasi solid-state flexible supercapacitors.
\end{abstract}

\section{Keywords}

Electrochemical double-layer capacitors; gel polymer electrolyte; carbon cloth; cyclic voltammetry; electrochemical impedance; specific capacitance; specific energy. 


\section{Introduction}

In recent years, there has been sharp increase in the development of flexible supercapacitors (FSCs) for electronic devices as power sources, which have to be ultra-thin and flexible in-order to serve their purpose [1-4]. FSCs with high specific energy, specific power and excellent cycle life are much desirable to supply the rising market of flexible and wearable electronic devices in the near future $[5,6]$.

To increase the performance of supercapacitors, the usage of various types of carbons, mixed/binary metal oxide and sulfide-based electrode materials like nanochains [7], nanoflowers [8] and other nanostructures [9-11] has been widely reported. Carbon based materials are most widely used electrode materials in supercapacitor application, due to their high surface area and capability of storing charge in the form of an electric-double layer [12,13]. Currently, reduced graphene oxide (RGO), a graphene-based material with high ionic conductivity and surface area, has emerged as a potential electrode material in FSCs and alternative to activated carbon [14]. The main components of a FSC are flexible electrodes, solid or quasi-solid-state electrolyte and a porous separator to prevent short-circuit [15]. The synergy between the electrolyte and the electrode material creates a significant impact on the properties of a supercapacitor, like charge-discharge capabilities, cyclic stability, energy storage in the form of charge, and power delivery [16].

The rate performance and specific power of a supercapacitor can be increased by increasing ionic conductivity of the electrolyte [17]. Most of FSC assemblies use gel polymer electrolytes (GPEs) to prevent leakage and packaging issues, as in the case of liquid electrolytes $[18,19]$. GPEs contain a discontinuous phase of solvent entrapped inside a continuous phase of three-dimensional polymer network [20]. Hydrogels of polyvinyl alcohol (PVA) contain hydroxyl groups which contribute to its hydrophilic nature by absorbing large amounts of water, in-turn enhancing the conductivity of electrolyte ions [26] and establishing stable contact at the interface of electrode and electrolyte [21].

Sulfonation of PVA hydrogels using proton donor like sulfuric acid $\left(\mathrm{H}_{2} \mathrm{SO}_{4}\right)$ enhances their ionic conductivity $[22,23]$. In the past, extensive usage of PVA- $\mathrm{H}_{2} \mathrm{SO}_{4}$ (SPVA) as GPE in supercapacitors has been reported alongside electrode materials like activated carbon [24], carbon nanotubes (CNTs) [25] and graphene [26-29]. Incorporation of nanofillers and redox-active materials into GPEs leads to rise in amorphous nature thereby improving ion conductivity [30, 31]. Recently, redox-additives like $\mathrm{Na}_{2} \mathrm{MoO}_{4}$ [5], hydroquinone [32], alizarin red [33] and indigo carmine [34] have been incorporated into $\mathrm{PVA}-\mathrm{H}_{2} \mathrm{SO}_{4}$ for application in supercapacitors.

Inorganic fillers like nano $\mathrm{SiO}_{2}$ [35], nano $\mathrm{TiO}_{2}$ [36], $\mathrm{Sb}_{2} \mathrm{O}_{3}$ [37] and graphene oxide (GO) [38] have been incorporated for improving performance in PVA based GPEs. Several reports have mentioned the usage of GO as a nanofiller in GPEs in various electrochemical devices [39-41]. Yang et al. [42] reported that incorporation of GO into polyvinylidene difluoride (PVDF) based GPE-enhances its ionic conductivity by forming 3D network structures in the polymer matrix facilitating the transport of ions.

The current paper deals with incorporation of hydrothermally reduced graphene oxide (HRG) into SPVA hydrogels, performed for the first time to obtain nanocomposite GPEs and evaluate their electrochemical performance for application in quasi solid state flexible supercapacitors. GO was synthesized using a modified Hummer's method and reduced hydrothermally to obtain HRG. Carbon cloth (CC) was modified using a hydrothermal method to obtain hydrothermally reduced carbon cloth (CCHy) and use it as a flexible current collector. Nanocomposite GPEs were prepared by sulfonating PVA hydrogel using $\mathrm{H}_{2} \mathrm{SO}_{4}$, followed by addition of calculated amounts of $\mathrm{HRG}$ ranging from 0.1 to 1.0 wt.\% to obtain HRG incorporated SPVA GPEs, hereafter referred as SPVA-HRG-x ( $x=$ content (wt.\%) of HRG). Electrochemical performance of developed SPVA-HRG-x was evaluated 
using an in-house fabricated supercapacitor single cell with electrodes of HRG coated CCHy (HRG-CCHy).

\section{Experimental}

\section{Materials}

Graphite powder (particle size $<20 \mu \mathrm{m}$ ) and sodium nitrate $\left(\mathrm{NaNO}_{3}\right)$ were obtained from SigmaAldrich Inc. and Merck Specialities Pvt. Ltd., India, respectively. Carbon cloth was obtained from Avcarb, USA. Ethanol 99.9 \% was procured from Changshu Hongsheng Fine Chemicals Co. Ltd., China. Poly (vinyl alcohol) (PVA) (M.W. 125,000), polyvinylidene difluoride (PVDF) (homopolymer powder, M.W. 320,000), N-methyl-2-pyrrolidone (NMP), sodium hydroxide ( $\mathrm{NaOH}$ ) pellets, sulphuric acid $\left(\mathrm{H}_{2} \mathrm{SO}_{4}\right) 98 \%$, hydrogen peroxide $\left(\mathrm{H}_{2} \mathrm{O}_{2}\right)(30 \% \mathrm{w} / \mathrm{v})$, hydrochloric acid $(\mathrm{HCl}) 35-38 \%$, and propan-2-ol (Isopropanol/IPA) were purchased from S D Fine-Chem Ltd., India. Potassium permanganate $\left(\mathrm{KMnO}_{4}\right)$ was obtained from Loba Chemie Pvt. Ltd., India. Whatman ${ }^{\circledR}$ qualitative filter paper: grade 1 (circles, diameter $125 \mathrm{~mm}$ ) purchased locally was used as a separator in two electrode studies. An in-house fabricated lab scale two electrode cell assembly made up of acrylic plates was used to carry out full-cell studies. Always deionized (DI) water was used in preparing various solutions.

\section{Method}

\section{Synthesis of HRG}

HRG was synthesized following the procedure reported in our previous work [43]. Firstly, a modified Hummer's method was followed for synthesizing GO. In 50 mL of conc. $\mathrm{H}_{2} \mathrm{SO}_{4}, 1 \mathrm{~g}$ of $\mathrm{NaNO}_{3}$ was added and stirred for few minutes, followed by dispersing $1 \mathrm{~g}$ of graphite powder into it. The above dispersion was stirred at $<5^{\circ} \mathrm{C}$ in an ice bath for $4 \mathrm{~h}$ continuously, followed by slow addition of $6 \mathrm{~g}$ of $\mathrm{KMnO}_{4}$. The above mixture was stirred uninterruptedly for $48 \mathrm{~h}$ at room temperature (RT). $92 \mathrm{~mL}$ of DI water was slowly added to the above mixture and stirred for two more hours. Later, $10 \mathrm{~mL}$ of $30 \% \mathrm{H}_{2} \mathrm{O}_{2}$ was added to the mixture leading to change in dispersion color from brown to yellow, indicating the formation of GO. The collected GO precipitate was washed with $1 \mathrm{M} \mathrm{HCl}$ and $\mathrm{DI}$ water and centrifuged. The resultant precipitate was finally washed using ethanol and vacuum dried at $70{ }^{\circ} \mathrm{C}$ for $12 \mathrm{~h}$. Later, the sample was finely crushed to obtain GO powder. $200 \mathrm{mg}$ of GO powder was dispersed in $200 \mathrm{~mL}$ through ultrasonication. The $\mathrm{pH}$ of the dispersion was maintained at 11 using $\mathrm{NaOH}$ pellets. The dispersion was then transferred into a Teflon ${ }^{\circledR}$ lined hydrothermal reactor $\left(300 \mathrm{~mL}\right.$ ) and autoclaved for $14 \mathrm{~h}$ at $180^{\circ} \mathrm{C}$. The precipitate collected after the reaction was washed several times using DI water and dried under vacuum for $12 \mathrm{~h}$ at $60^{\circ} \mathrm{C}$. The dried sample was crushed to obtain a fine powder of HRG.

\section{Preparation of $\mathrm{CCHy}$}

$\mathrm{CCHy}$ was prepared following the procedure reported in our previous work [44]. Commercially obtained carbon cloth (CC) $\left(50 \mathrm{~cm}^{2}\right)$ was oxidized via chemical route. An acidic mixture of $20 \mathrm{~mL}$ of $\mathrm{H}_{2} \mathrm{SO}_{4}$ and $10 \mathrm{~mL}$ of $\mathrm{HNO}_{3}$ was prepared into which a pristine $\mathrm{CC}$ was dropped and stirred at RT, followed by slow addition of $3 \mathrm{~g}$ of $\mathrm{KMnO}_{4}$ and $100 \mathrm{~mL}$ of DI water, and stirred for $3 \mathrm{~h}$. Later, $5-10 \mathrm{~mL}$ of $30 \% \mathrm{H}_{2} \mathrm{O}_{2}$ was added to the above mixture resulting in a clear solution with oxidized carbon cloth in it. The oxidized CC was washed with DI water and transferred into a Teflon ${ }^{\circledR}$ lined hydrothermal reactor $(300 \mathrm{~mL})$, filled with $\mathrm{DI}$ water and autoclaved for $14 \mathrm{~h}$ at $180^{\circ} \mathrm{C}$. Later, the reduced CC was 
vacuum dried at $70^{\circ} \mathrm{C}$ for $6 \mathrm{~h}$. The hydrothermally reduced $\mathrm{CC}(\mathrm{CCHy})$ thus obtained was used as a current collector in the following two electrode cell studies.

Preparation of SPVA

To prepare SPVA, $270 \mu \mathrm{L}$ of $\mathrm{H}_{2} \mathrm{SO}_{4}$ was added to $4 \mathrm{~mL}$ of DI water. Then, $0.5 \mathrm{~g}$ of PVA was added to this mixture, and stirred at $80^{\circ} \mathrm{C}$ till all PVA gets dissolved, resulting in a transparent viscous liquid.

Preparation of SPVA-HRG-x

HRG based SPVA nanocomposite was prepared by adding predetermined quantities of HRG ranging from 0.1 to $1.0 \mathrm{wt}$ \% to SPVA, separately. The HRG was dispersed in IPA using ultrasonication and added to the cooled SPVA and stirred continuously at $80^{\circ} \mathrm{C}$ for $30 \mathrm{~min}$, resulting in dark coloured SPVA-HRG-x. The obtained SPVA-HRG-x were coded as SPVA-HRG-0.1, SPVA-HRG0.2, SPVA-HRG-0.5 and SPVA-HRG-1.0 for SPVA incorporated with 0.1, 0.2, 0.5 and 1.0 wt. \% of HRG, respectively. Figure 1 shows the optical images of prepared SPVA and SPVA-HRG-x.

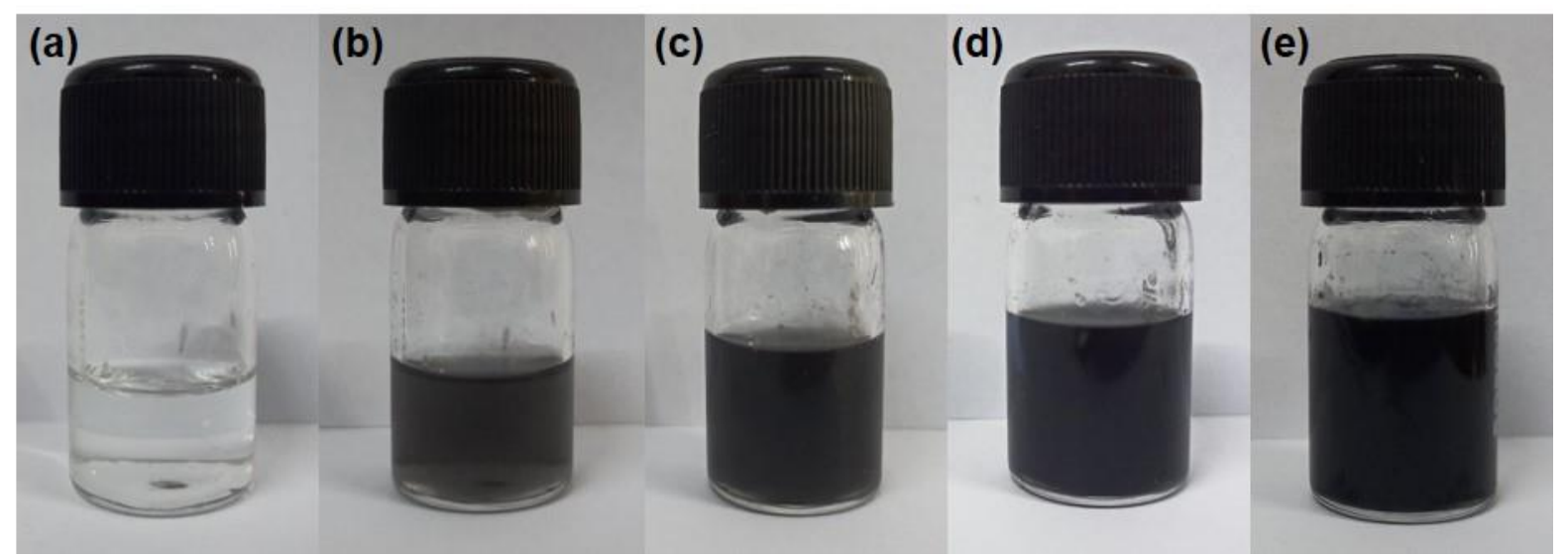

Figure 1. Optical images of (a) SPVA; (b) SPVA-HRG-0.1; (c) SPVA-HRG-0.2; (d) SPVA-HRG-0.5;

(e) SPVA-HRG-1.0

\section{Characterization studies}

X-ray diffraction (XRD) technique (Rigaku Miniflex 600) was used to analyse all GPEs. Electrochemical workstation (PARSTAT PMC 2000A) was used to evaluate the electrochemical performance of prepared SPVA-HRG-x. HRG-CCHy was prepared by coating HRG $\left(1 \mathrm{mg} \mathrm{cm}^{-2}\right)$ over CCHy. Ink of HRG was prepared by dispersing $1.8 \mathrm{mg}$ of HRG in $100 \mu \mathrm{L}$ of NMP along with $2 \mu \mathrm{L}$ of 10 wt. \% PVDF/NMP solution by ultrasonication. HRG ink was then deposited over flexible CCHy current collectors, followed by drying under vacuum for $15 \mathrm{~min}$ at $120^{\circ} \mathrm{C}$. Strands of HRG coated $\mathrm{CCHy}$ (HRG-CCHy) were placed on both sides of a GPE coated Whatman ${ }^{\circledR}$ filter paper and packed in between acrylic plates tightly to fabricate a cell. Approximately, $100 \mu \mathrm{L}$ of GPE was utilized during fabrication each cell. The prepared cell was then tested in two electrode configuration using cyclic voltammetry (CV), galvanostatic charge-discharge (GCD) and electrochemical impedance spectroscopy (EIS) techniques to evaluate the performance of SPVA-HRG-X.

The specific capacitance $\left(C_{\mathrm{s}}\right)$, specific energy $\left(E_{\mathrm{d}}\right)$ and specific power $\left(P_{\mathrm{d}}\right)$ of HRG-CCHy in all GPEs were calculated from GCD data, using the equations (1) to (3) [45].

$$
C_{s}=2 \frac{I \Delta t}{m \Delta V}
$$




$$
\begin{aligned}
& E_{\mathrm{d}}=\frac{C_{\mathrm{s}} \Delta V^{2}}{8} \\
& P_{\mathrm{d}}=\frac{E_{\mathrm{d}}}{\Delta t}
\end{aligned}
$$

where / represent constant discharge current, $\Delta t$ represents discharge time, $\Delta V$ represents discharge potential window and $m$ represents the mass of the active material on one electrode.

\section{Results and discussion}

\section{$X R D$ analysis}

Figure 2 shows X-ray diffraction patterns of pure PVA, SPVA and SPVA-HRG-x. The diffraction pattern of pure PVA shows a characteristic semi-crystalline peak at $2 \theta$ value of around 19.6 [46]. In the case of SPVA, $\mathrm{H}_{2} \mathrm{SO}_{4}$ addition disturbs the semi-crystalline nature of pure PVA, thereby increasing its amorphous nature [47]. From diffraction patterns of all SPVA-HRG-x it can be inferred that by increase in HRG concentration the intensity of peak around $2 \theta$ value of 19.6 decreased, indicating an increase in amorphous nature of GPEs [48]. The addition of HRG may contribute to the increase in amorphous nature of the SPVA-HRG-x [42], thereby enhancing the rate of penetration and conduction of ions [49].

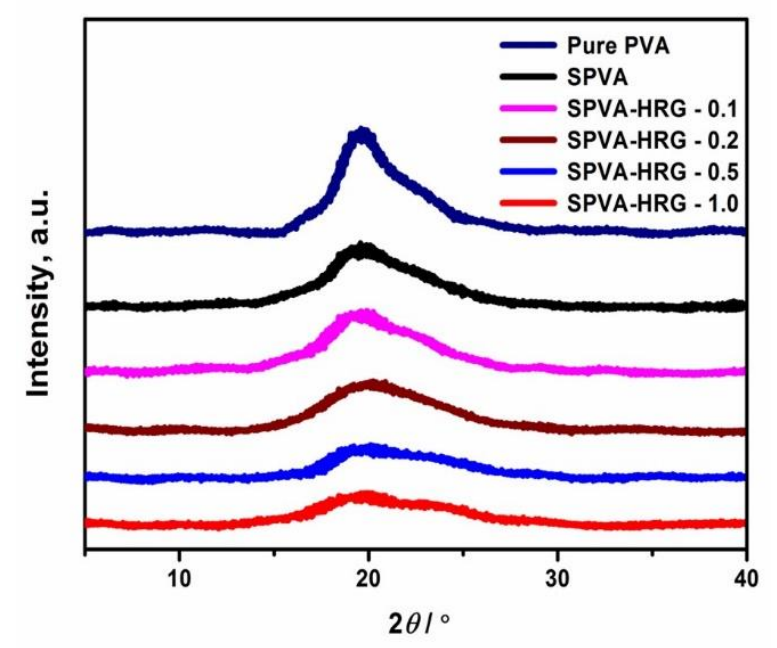

Figure 2. X-ray diffraction patterns of pure PVA, SPVA, SPVA-HRG-0.1, SPVA-HRG-0.2, SPVA-HRG-0.5 and SPVA-HRG-1.0

\section{Electrochemical studies}

\section{CV studies}

The electrochemical performance of HRG-CCHy was evaluated by executing CV studies for all five GPEs at various scan rates, ranging from 10 to $100 \mathrm{mV} \mathrm{s}^{-1}$, within potential window 0 to $1 \mathrm{~V}$. The area under near rectangular CV curve is proportional to the double-layer capacitance of the electrode material [50]. Figure 3a compares CV curves of HRG-CCHy in all GPEs at the scan rate of $50 \mathrm{mV} \mathrm{s}^{-1}$, with HRG-CCHy showing comparatively superior double-layer capacitance in SPVA-HRG0.5 electrolyte. From CV curves of HRG-CCHy in all GPEs depicted in Figure 3a, an increase of the area under near rectangular CV curve is observed by increasing HRG content in SPVA-HRG-x electrolyte up to $0.5 \mathrm{wt}$.\%. The decrease in CV curve area of HRG-CCHy in SPVA-HRG-1.0 compared 
to SPVA-HRG-0.5, indicates a decline in double-layer capacitance of HRG-CCHy in SPVA-HRG-1.0 due to the excess concentration of HRG in SPVA-HRG-1.0, which could resist the flow of ions due to formation of agglomerates by restacking of HRG layers $[45,48]$. The CV curves of HRG-CCHy in SPVAHRG-0.5 electrolyte at multiple scan rates ranging from 10 to $100 \mathrm{mV} \mathrm{s}^{-1}$ (Figure $3 \mathrm{~b}$ ), indicate better rate capability and reversibility [51].
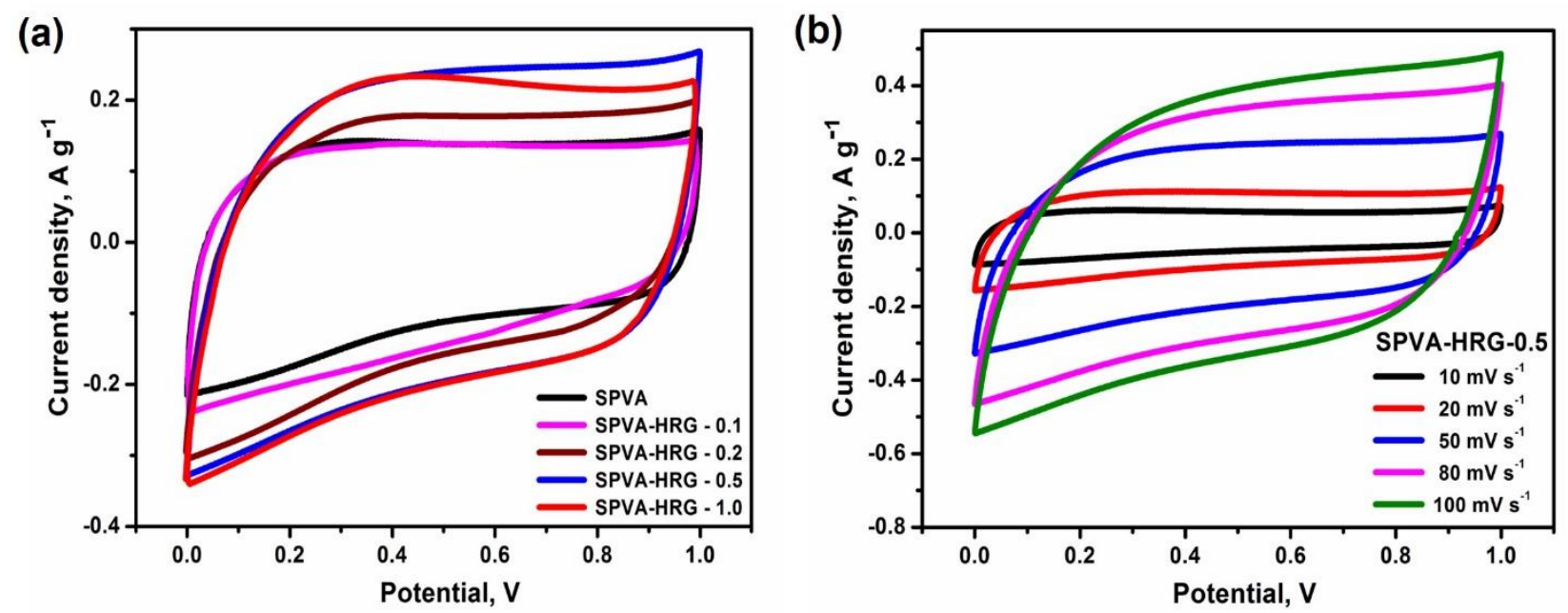

Figure 3. (a) Comparative CV curves of HRG-CCHy in SPVA, SPVA-HRG-0.1, SPVA-HRG-0.2, SPVA-HRG-0.5 and SPVA-HRG-1.0 at scan rate of $50 \mathrm{mV} \mathrm{s}^{-1}$; (b) CV curves of HRG-CCHy in SPVA-HRG-0.5 at scan rates ranging from 10 to $100 \mathrm{mV} \mathrm{s}^{-1}$

\section{GCD studies}

The charge-discharge behaviour of HRG-CCHy in all five GPEs was evaluated by performing GCD studies at various constant current densities ranging from 0.5 to $10 \mathrm{~A} \mathrm{~g}^{-1}$, within the potential window 0 to $1 \mathrm{~V}$. Figure 4 a compares GCD curves of HRG-CCHy in all GPEs at $1 \mathrm{~A} \mathrm{~g}^{-1}$. It is obvious that HRGCCHy shows better charging and discharging ability in SPVA-HRG-0.5 electrolyte, compared to the rest of the GPEs, with an impressive specific capacitance of $200 \mathrm{~F} \mathrm{~g}^{-1}$ at $1 \mathrm{~A} \mathrm{~g}^{-1}$ with lowest IR drop of around 0.07 V. Figure 4b shows GCD curves of HRG-CCHy in SPVA-HRG-0.5 electrolyte at multiple constant current densities ranging from 0.5 to $10 \mathrm{~A} \mathrm{~g}^{-1}$. Figure 4c represents the IR drop plot of HRG-CCHy in all GPEs at various constant current densities ranging from 0.5 to $10 \mathrm{~A} \mathrm{~g}^{-1}$, indicating the lower equivalent series resistance (ESR) and superior conductivity of HRG-CCHy when SPVA-HRG-0.5 was used as electrolyte [52]. Figure 4d represents the Ragone plot of HRG-CCHy in all GPEs, indicating superior specific energy to power ratio of HRG-CCHy in SPVA-HRG-0.5, like $6.1 \mathrm{Wh} \mathrm{kg}^{-1}$ of specific energy at specific power of $1 \mathrm{~kW} \mathrm{~kg}^{-1}$. In SPVA-HRG-1.0 electrolyte, HRG-CCHy showed a sharp increase in IR drop and decrease in specific energy at current densities $\geq 7 \mathrm{~A} \mathrm{~g}^{-1}$, indicating an abrupt increase of ESR of the cell. This distinct behavior of SPVA-HRG-1.0 electrolyte at higher current densities, could result from the excess of HRG in SPVA-HRG-1.0, which could lead to restacking of HRG layers forming agglomerates, in-turn resisting the flow of ions $[39,42]$.

Cyclic stability

Figure 5a represents the cyclic stability of HRG-CCHy in all GPEs for 5000 GCD cycles at $2 \mathrm{~A} \mathrm{~g}^{-1}$. Even after 5000 GCD cycles, HRG-CCHy retained 82, 86, 89, 93 and $87 \%$ of their initial specific capacitances in SPVA, SPVA-HRG-0.1, SPVA-HRG-0.2, SPVA-HRG-0.5 and SPVA-HRG-1.0, respecttively. Figure 5b shows GCD curves of HRG-CCHy in SPVA-HRG-0.5 before and after cycling for 5000 cycles, which clearly establishes the notable charge-discharge stability of HRG-CCHy in 
SPVA-HRG-0.5. Table 1 represents the comparison of supercapacitive performances of some carbonbased electrode materials in sulfonated PVA based GPEs.

(a)

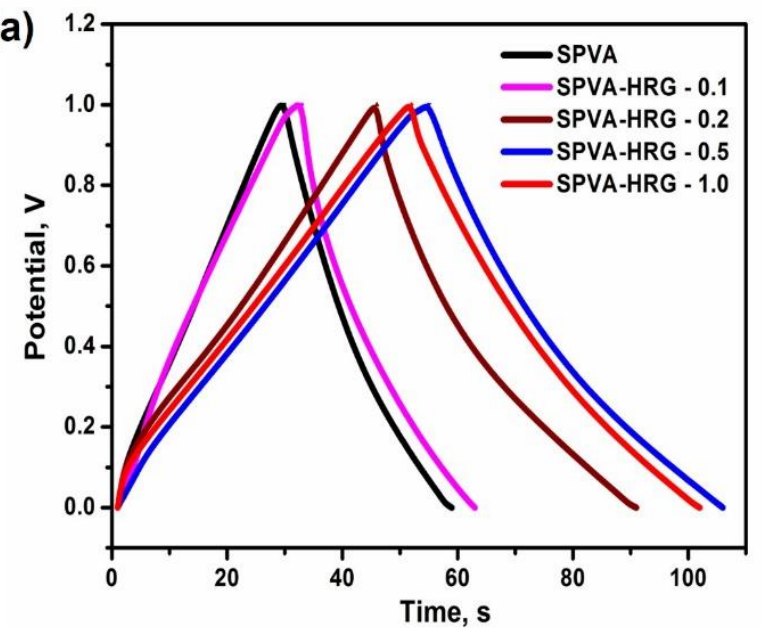

(c)

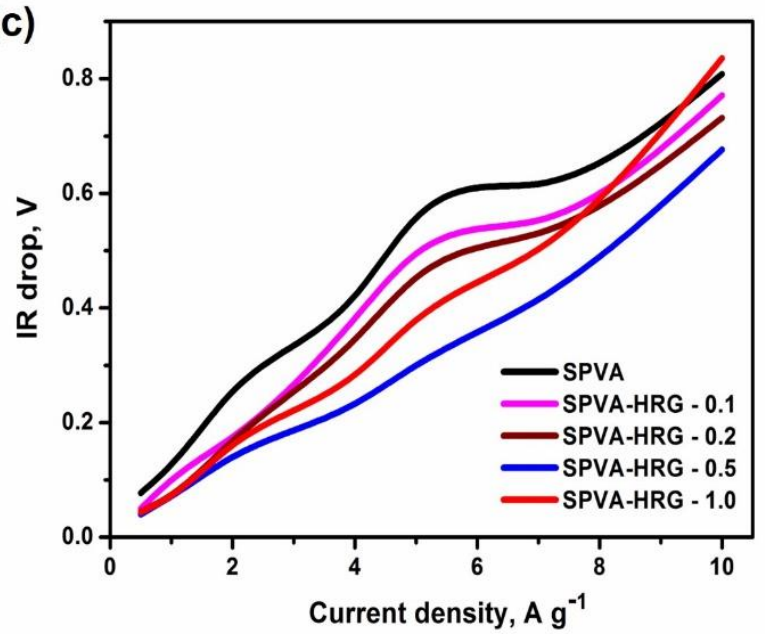

(b)

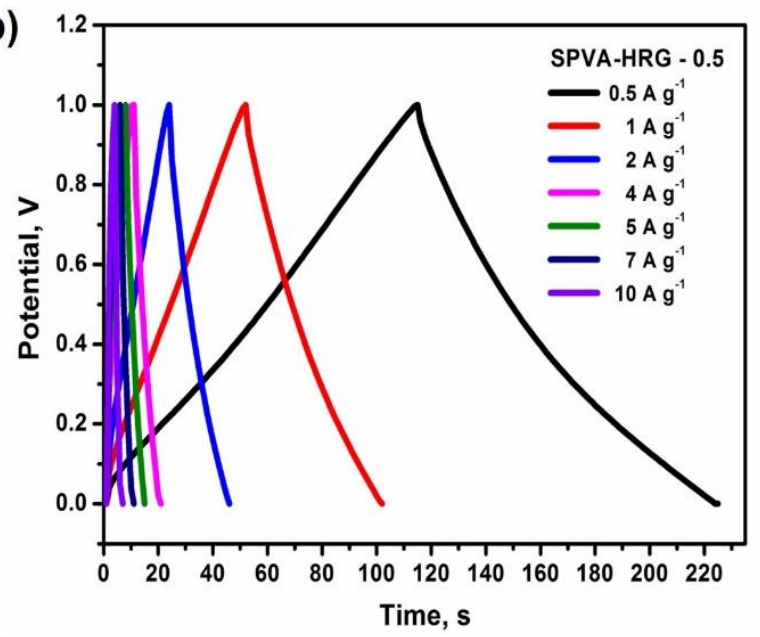

(d)

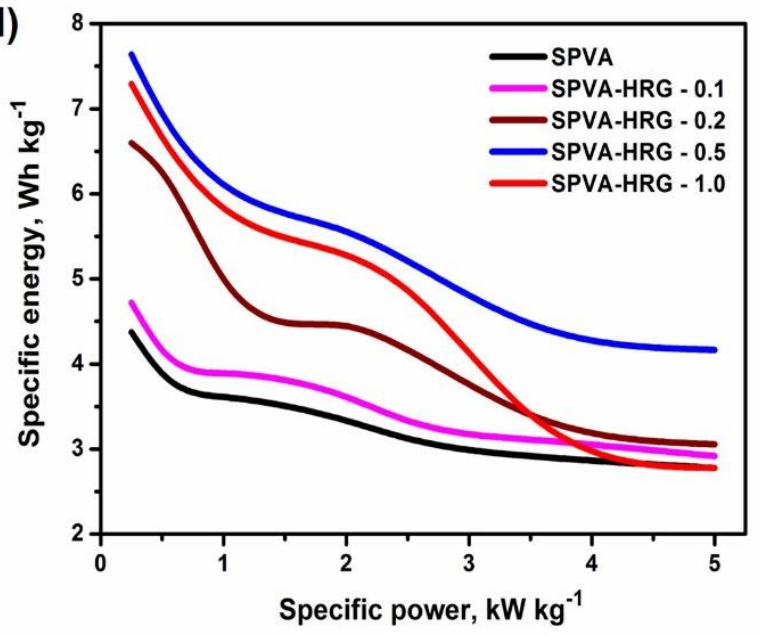

Figure 4. (a) GCD curves of HRG-CCHy in SPVA, SPVA-HRG-0.1, SPVA-HRG-0.2, SPVA-HRG-0.5 and SPVAHRG-1.0 at $1 \mathrm{~A} \mathrm{~g}^{-1}$; (b) GCD curves of HRG-CCHy in SPVA-HRG-0.5 at 0.5, 1, 2, 4, 5, 7 and $10 \mathrm{~A} \mathrm{~g}^{-1}$; (c) IR drop plot; (d) Ragone plot of HRG-CCHy in SPVA, SPVA-HRG-0.1, SPVA-HRG-0.2, SPVA-HRG-0.5 and SPVA-HRG-1.0
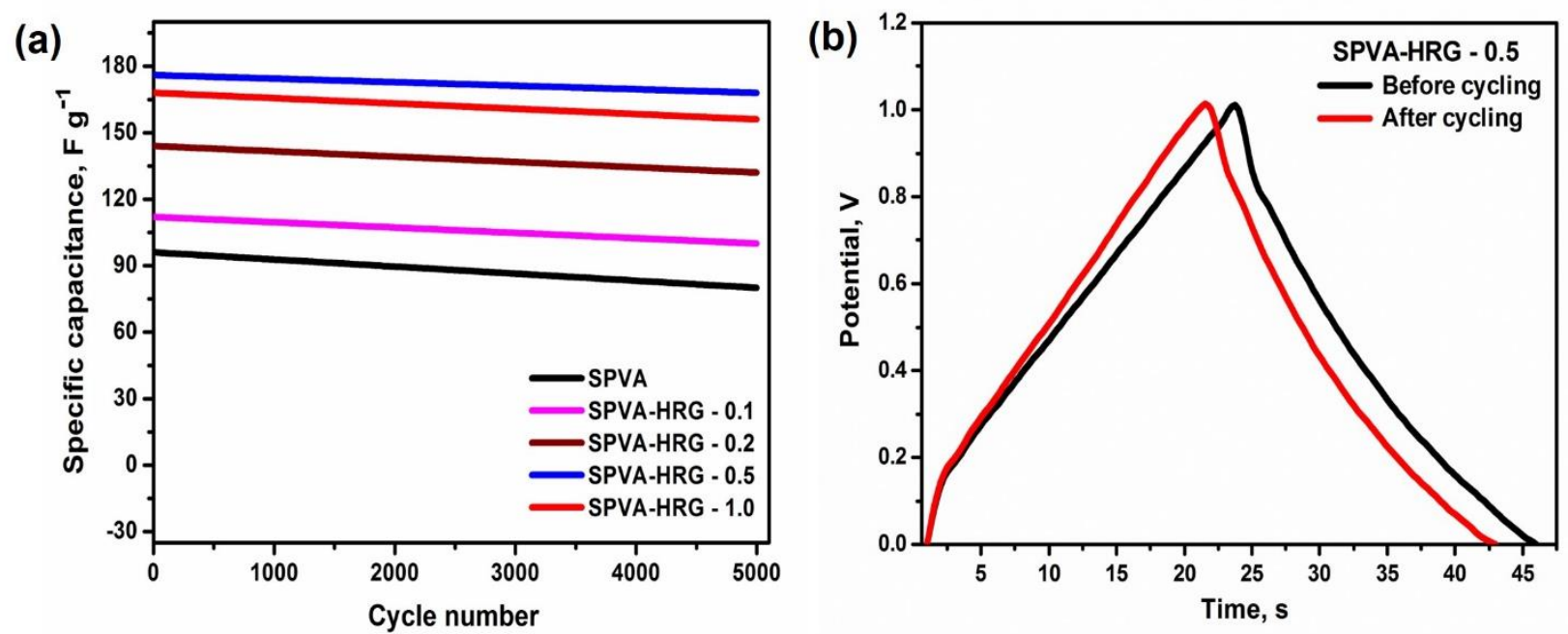

Figure 5. (a) Cyclic stability of HRG-CCHy in SPVA, SPVA-HRG-0.1, SPVA-HRG-0.2, SPVA-HRG-0.5 and SPVA-HRG-1.0 at $2 \mathrm{~A} \mathrm{~g}^{-1}$ for 5000 GCD cycles; (b) GCD curves of HRG-CCHy in SPVA-HRG-0.5 before and after cycling for $5000 \mathrm{GCD}$ cycles at $2 \mathrm{~A} \mathrm{~g}^{-1}$ 
Table 1. Comparison of supercapacitive performances of carbon-based electrode materials in sulfonated PVA based GPES

\begin{tabular}{cccc}
\hline Electrolyte & Electrode material & Specific capacitance & Reference \\
\hline $\mathrm{PVA} / \mathrm{H}_{2} \mathrm{SO}_{4}$ & Graphene & $190 \mathrm{~F} \mathrm{~g}^{-1}$ at $0.5 \mathrm{~A} \mathrm{~g}^{-1}$ & {$[28]$} \\
\hline $\mathrm{PVA} / \mathrm{H}_{2} \mathrm{SO}_{4}$ & RGO-PVA composite film & $184.6 \mathrm{~F} \mathrm{~g}^{-1}$ at $1 \mathrm{~A} \mathrm{~g}^{-1}$ & {$[53]$} \\
\hline $\mathrm{PVA} / \mathrm{H}_{2} \mathrm{SO}_{4}$ & $\mathrm{~N}$-doped porous carbon & $232 \mathrm{~F} \mathrm{~g}^{-1}$ at $0.5 \mathrm{~A} \mathrm{~g}^{-1}$ & {$[54]$} \\
\hline $\mathrm{PVA} / \mathrm{H}_{2} \mathrm{SO}_{4} / \mathrm{H}_{3} \mathrm{BO}_{3}$ & Poly carbon nanofibers & $134 \mathrm{~F} \mathrm{~g}^{-1}$ at $1 \mathrm{~A} \mathrm{~g}^{-1}$ & {$[23]$} \\
\hline $\mathrm{PVA} / \mathrm{H} 2 \mathrm{SO}_{4} / \mathrm{Na}_{2} \mathrm{MoO} 4$ & $\mathrm{MoS}-\mathrm{NCNT}$ & $95.14 \mathrm{~F} \mathrm{~g}^{-1}$ at $1 \mathrm{~mA}$ & {$[55]$} \\
\hline $\mathrm{PVA} / \mathrm{H}_{2} \mathrm{SO}_{4} / \mathrm{HRG}-0.5$ & $\mathrm{HRG}$ & $200 \mathrm{~F} \mathrm{~g}^{-1}$ at $1 \mathrm{~A} \mathrm{~g}^{-1}$ & Present work \\
\hline
\end{tabular}

EIS studies

The EIS studies were performed at $a c$ amplitude of $5 \mathrm{mV}$ and within the frequency range of $100 \mathrm{kHz}$ to $0.1 \mathrm{~Hz}$. Figure 6a represents Nyquist plots of HRG-CCHy in all five GPEs. For all SPVA-HRG- $x$, the imaginary impedance part in the low frequency region was near perpendicular to the real axis, indicating near ideal capacitive behaviour of the cell. From Nyquist plots, it is evident that HRG-CCHy has low impedance in SPVA-HRG-0.5 compared to other GPEs [56]. The inset image of Figure 6a exhibits the magnified image of Nyquist plots, where SPVA-HRG-0.5 electrolyte showed lower electrolyte resistance compared to other GPEs [57]. Figure 6b represents the Nyquist plot of HRG-CCHy in SPVA-HRG- 0.5 before and after 5000 GCD cycles. The size of the semicircle in the high frequency region of the Nyquist plot indicates charge transfer resistance [58,59]. The inset image of Figure $6 \mathrm{~b}$ exhibits the magnified image of Nyquist plots, where it can be inferred that diameter of the semi-circle of SPVA-HRG-0.5 increased after cycling 5000 GCD cycles. This confirms the increase of charge transfer resistance after cycling $[57,58]$. Near-vertical line observed in the low frequency region of Nyquist plot for SPVA-HRG-0.5 indicates superior capacitive behaviour compared to other GPEs [60].
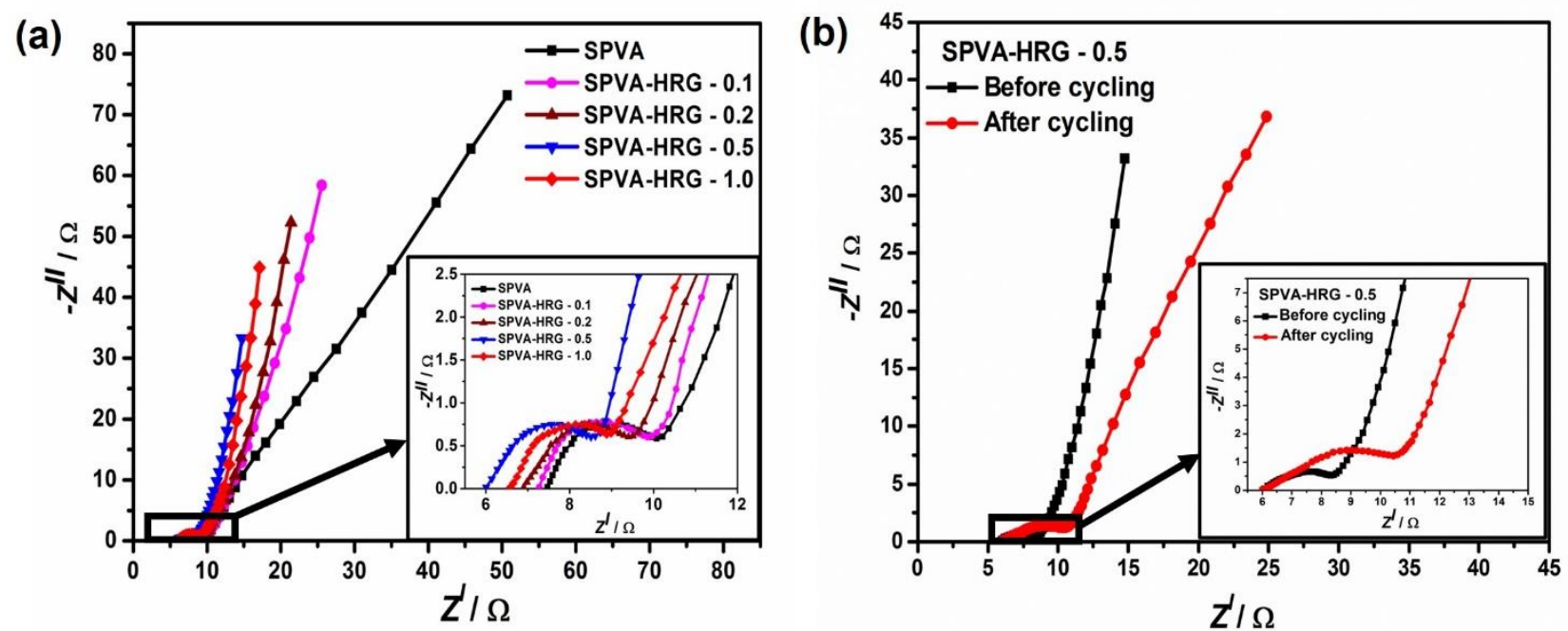

Figure 6. (a) Nyquist plots of HRG-CCHy in SPVA, SPVA-HRG-0.1, SPVA-HRG-0.2, SPVA-HRG-0.5 and SPVA-HRG-1.0. Inset image represents the magnified high frequency part of Nyquist plots; (b) Nyquist plots of HRG-CCHy in SPVA-HRG-0.5 before and after cycling for 5000 GCD cycles at $2 \mathrm{~A} \mathrm{~g}^{-1}$. Inset image represents the magnified high frequency part of Nyquist plots

\section{Conclusion}

SPVA-HRG-x were prepared by introducing HRG into SPVA and characterized using XRD technique. Supercapacitor assembled by using HRG-CCHy and GPEs was characterized by CV, GCD 
and EIS. As confirmed by XRD measurements, SPVA-HRG-x may have induced amorphous nature, improving thereby ionic conductivity and lowering impedance. HRG-CCHy in SPVA-HRG-0.5 exhibited a specific capacitance of $200 \mathrm{~F} \mathrm{~g}^{-1}$ at $1 \mathrm{~A} \mathrm{~g}^{-1}$ with the lowest IR drop of around $0.07 \mathrm{~V}$ and an impressive specific energy of $6.1 \mathrm{Wh} \mathrm{kg}^{-1}$ at the specific power of $1 \mathrm{~kW} \mathrm{~kg}^{-1}$. Even after $5000 \mathrm{GCD}$ cycles, HRG-CCHy retained $93 \%$ of its initial capacitance in SPVA-HRG-0.5. The notable performance of HRG-CCHy in SPVA-HRG-0.5 may be attributed to the relatively lower impedance in SPVA-HRG-0.5. From the performed electrochemical studies, it can be inferred that SPVA-HRG-0.5 can be considered as a potential GPE for application in quasi solid-state flexible supercapacitors.

Acknowledgements: The authors are grateful to Er Koneru Satyanarayana Garu, Hon'ble President, Koneru Lakshmaiah Education Foundation (Deemed to be University) for in-house funding to carry out this work. The authors also thank the CoEXAMMPC, VFSTR, Guntur, AP for X-ray diffraction (XRD) measurement.

\section{References}

[1] J. Liang, B. Tian, S. Li, C. Jiang, W. Wu, Advanced Energy Materials 10 (2020) 2000022. https://doi.org/10.1002/aenm.202000022

[2] J. Liu, J. Ye, F. Pan, X. Wang, Y. Zhu, Science China Materials 62 (2019) 545-554. https://doi.org/10.1007/s40843-018-9309-x

[3] J. Ben, Z. Song, X. Liu, W. Lu, X. Liu, Nanoscale Research Letters 15 (2020) 151. https://doi.org/10.1186/s11671-020-03379-w

[4] A. K. Yedluri, S. Sambasivam, S. A. Hira, K. Zeb, W. Uddin, T. N. V. Krishna, K. D. Kumar, I. M. Obaidat, H. J. Kim, Electrochimica Acta 364 (2020) 137318. https://doi.org/10.1016/i.electacta.2020.137318

[5] M. Sandhiya, S. Suresh Balaji, M. Sethish, Energy \& Fuels 34(9) (2020) 11536-11546. https://doi.org/10.1021/acs.energyfuels.0c02199

[6] B. Cai, C. Shao, L. Qu, Y. Meng, L. Jin, Frontiers of Materials Science 13 (2019) 145-153. https://doi.org/10.1007/s11706-019-0455-2

[7] A..K. Yedluri, S. Singh, P..J..S. Rana, K..D. Kumar, H.-J. Kim, New Journal of Chemistry 44 (2020) 4266-4275. https://doi.org/10.1039/C9NJ06318H

[8] A. K. Yedluri, K. D. Kumar, H.-J. Kim, Dalton Transactions 49 (2020) 3622-3629. https://doi.org/10.1039/DODT00268B

[9] A. K. Yedluri, K. D. Kumar, H.-J. Kim, Dalton Transactions 49 (2020) 4050-4059 https://doi.org/10.1039/D0DT00191K

[10] A. K. Yedluri, D. K. Kulurumotlakatla, S. Sangaraju, I. M. Obaidat, H.-J. Kim, Journal of Energy Storage 31 (2020) 101623. https://doi.org/10.1016/i.est.2020.101623

[11] A. K. Yedluri, K. D. Kumar, H.-J. Kim, Electrochimica Acta 330 (2020) 135261. https://doi.org/10.1016/i.electacta.2019.135261

[12] G. Zhang, Y. Chen, Y. Chen, H. Guo, Materials Research Bulletin 102 (2018) 391-398. https://doi.org/10.1016/j.materresbull.2018.03.006

[13] D. Wang, L. Xu, Y. Wang, W. Xu, Journal of Electroanalytical Chemistry 815 (2018) 166-174. https://doi.org/10.1016/j.jelechem.2018.03.016

[14] X. Chen, R. Paul, L. Dai, National Science Review 4 (2017) 453-489. https://doi.org/10.1093/nsr/nwx009

[15] D. P. Dubal, N. R. Chodankar, D.-H. Kim, P. R. Gomez, Chemical Society Reviews 47 (2018) 2065-2129. https://doi.org/10.1039/C7CS00505A

[16] S. Alipoori, S. Mazinani, S. H. Aboutalebi, F. Sharif, Journal of Energy Storage 27 (2020) 101072. https://doi.org/10.1016/j.est.2019.101072

[17] Y. Wang, Z. Chang, M. Qian, Z. Zhang, J. Lin, F. Huang, Carbon 143 (2019) 300-308. https://doi.org/10.1016/j.carbon.2018.11.033 
[18] X. Lu, M. Yu, G. Wang, Y. Tong, Y. Li, Energy \& Environmental Science 7 (2014) 2160-2181. https://doi.org/10.1039/C4EE00960F

[19] Y.-G. Cho, C. Hwang, D. S. Cheong, Y.-S. Kim, H.-K. Song, Advanced Materials 31 (2019) 1804909. https://doi.org/10.1002/adma.201804909

[20] M. Rosi, F. Iskandar, M. Abdullah, Khairurrijal, International Journal of Electrochemical Science 9 (2014) 4251-4256. https://1library.net/document/oy875xwz-hydrogel-polymerelectrolytes-polyvinyl-alcohol-hydroxyethylcellulose-supercapacitor-applications.html

[21] Q.-M. Tu, L.-Q. Fan, F. Pan, J.-L. Huang, Y. Gu, J.-M. Lin, M.-L. Huang, Y.-F. Huang, J.-H. Wu, Electrochimica Acta 268 (2018) 562-568. https://doi.org/10.1016/j.electacta.2018.02.008

[22] A. A. Łatoszyńska, P.-L. Taberna, P. Simon, W. Wieczorek, Electrochimica Acta 242 (2017) 31-37. https://doi.org/10.1016/i.electacta.2017.04.122

[23] B. Karaman, A. Bozkurt, International Journal of Hydrogen Energy 43 (2018) 6229-6237. https://doi.org/10.1016/J.IJHYDENE.2018.02.032

[24] M. Areir, Y. Xu, D. Harrison, J. Fyson, R. Zhang, Materials and Manufacturing Processes 33 (2018) 905-911. https://doi.org/10.1080/10426914.2017.1401712

[25] K. Prasannan, R. Natarajan, S.D. Kaveripatnam, ChemPhysChem 14(16) (2013) 3822-3826. https://doi.org/10.1002/cphc.201300622

[26] R. Singh, C. C. Tripathi, Materials Today: Proceedings 5 (2018) 1125-1130. https://doi.org/10.1016/i.matpr.2017.11.192

[27] J. Ye, H. Tan, S. Wu, K. Ni, F. Pan, J. Liu, Z. Tao, Y. Qu, H. Ji, P. Simon, Y. Zhu, Advanced Materials 30 (2018) 1801384. https://doi.org/10.1002/adma.201801384

[28] Y. L. Li, P. C. Li, B. J. Li, M. K. Gao, F. Y. Zhao, L. Shao, J. F. Chen, L. H. Li, International Journal of Electrochemical Science 12 (2017) 10567-10576. https://doi.org/10.20964/2017.11.32

[29] D. Ghosh, S.O. Kim, Electronic Materials Letters 11 (2015) 719-734. https://doi.org/10.1007/s13391-015-9999-1

[30] M. Jiang, J. Zhu, C. Chen, Y. Lu, Y. Ge, X. Zhang, ACS Applied Materials \& Interfaces 8 (2016) 3473-3481. https://doi.org/10.1021/acsami.5b11984

[31] K. Sun, M. Dong, E. Feng, H. Peng, G. Ma, G. Zhao, Z. Lei, RSC Advances 5 (2015) 2241922425. https://doi.org/10.1039/C4RA15484C

[32] R. Xu, F. Guo, X. Cui, L. Zhang, K. Wang, J. Wei, Journal of Materials Chemistry A 3 (2015) 22353-22360. https://doi.org/10.1039/C5TA06165B

[33] K. Sun, F. Ran, G. Zhao, Y. Zhu, Y. Zheng, M. Ma, X. Zheng, G. Ma, Z. Lei, RSC Advances 6 (2016) 55225-55232. https://doi.org/10.1039/C6RA06797B

[34] G. Ma, M. Dong, K. Sun, E. Feng, H. Peng, Z. Lei, Journal of Materials Chemistry A 3 (2015) 4035-4041. https://doi.org/10.1039/C4TA06322H

[35] H. Gao, K. Lian, Journal of The Electrochemical Society 160 (2013) A505. https://doi.org/10.1149/2.053303jes/meta

[36] C.-S. Lim, K.H. Teoh, C.-W. Liew, S. Ramesh, Materials Chemistry and Physics 143(2) (2014) 661-667. https://doi.org/10.1016/i.matchemphys.2013.09.051

[37] C.-S. Lim, K. H. Teoh, C.-W. Liew, S. Ramesh, Ionics 20 (2014) 251-258. https://doi.org/10.1007/s11581-013-0982-2

[38] Y. F. Huang, P. F. Wu, M. Q. Zhang, W. H. Ruan, E. P. Giannelis, Electrochimica Acta 132 (2014) 103-111. https://doi.org/10.1016/j.electacta.2014.03.151

[39] Y. S. Ye, M. Y. Cheng, X. L. Xie, J. Rick, Y. J. Huang, F. C. Chang, B. J. Hwang, Journal of Power Sources 239 (2013) 424-432. https://doi.org/10.1016/i.jpowsour.2013.03.021

[40] J. Gun, S. A. Kulkarni, W. Xiu, S. K. Batabyal, S. Sladkevich, P. V. Prikhodchenko, V. Gutkin, O. Lev, Electrochemistry Communications 19 (2012) 108-110.

https://doi.org/10.1016/i.elecom.2012.03.025 
[41] Y. C. Cao, C. Xu, X. Wu, X. Wang, L. Xing, K. Scott, Journal of Power Sources 196 (2011) 8377838. https://doi.org/10.1016/i.jpowsour.2011.06.074

[42] X. Yang, F. Zhang, L. Zhang, T. Zhang, Y. Huang, Y. Chen, Advanced Functional Materials 23 (2013) 3353-3360. https://doi.org/10.1002/adfm.201203556

[43] S. S. Rajaputra, N. Pennada, A. Yerramilli, N. M. Kummara, Ionics (2021) https://doi.org/10.1007/s11581-021-04144-4

[44] S. S. Rajaputra, N. Pennada, A. Yerramilli, N. M. Kummara, Journal of Electrochemical Energy Conversion and Storage 18(4) (2021) 041008. https://doi.org/10.1115/1.4051143

[45] H. Wang, H. Yi, X. Chen, X. Wang, Journal of Materials Chemistry A 2 (2014) 3223-3230. https://doi.org/10.1039/C3TA15046A

[46] A. Hany, M. A. Mousa, T. El-Essawy, Journal of Basic and Environmental Sciences 4 (2017) 298-304. https://ibesci.org/published/4.4.2.pdf

[47] E. Sheha, M. K. El-Mansy, Journal of Power Sources 185 (2008) 1509-1513. https://doi.org/10.1016/j.jpowsour.2008.09.046

[48] Y. Pavani, M. Ravi, S. Bhavani, A. K. Sharma, V. V. Narasimha Rao, Polymer Engineering \& Science 52 (2012) 1685-1692. https://doi.org/10.1002/pen.23118

[49] R. M. Hodge, G. H. Edward, G. P. Simon, Polymer 37 (1996) 1371-1376. https://doi.org/10.1016/0032-3861(96)81134-7

[50] K. Ghosh, C. Y. Yue, Electrochimica Acta 276 (2018) 47-63. https://doi.org/10.1016/j.electacta.2018.04.162

[51] M. P. Kumar, T. Kesavan, G. Kalita, P. Ragupathy, T. N. Narayanan, D. K. Pattanayak, RSC advances 4 (2014) 38689-38697. https://doi.org/10.1039/C4RA04927F

[52] X. Lu, Y. Zeng, M. Yu, T. Zhai, C. Liang, S. Xie, M. S. Balogun, Y. Tong, Advanced Materials 26 (2014) 3148-315.5 https://doi.org/10.1002/adma.201305851

[53] J. Cao, C. Chen, K. Chen, Q. Lu, Q. Wang, P. Zhou, D. Liu, L. Song, Z. Niu, J. Chen, Journal of Materials Chemistry A 5 (2017) 15008-15016. https://doi.org/10.1039/C7TA04920J

[54] N. Deka, J. Deka, G. K. Dutta, Chemistry Select 3 (2018) 8483-8490. https://doi.org/10.1002/slct.201801507

[55] S. P. S. Moopri, G. K. Veerasubramani, R. M. Bhattarai, G. Gnanasekaran, S. J. Kim, Y. S. Mok, ACS Applied Energy Materials 4 (2021) 2218-2230.

https://doi.org/10.1021/acsaem.0c02739

[56] H. Yu, J. Wu, L. Fan, K. Xu, X. Zhong, Y. Lin, J. Lin, Electrochimica Acta 56 (2011) 6881-6886. https://doi.org/10.1016/i.electacta.2011.06.039

[57] Q. Chen, X. Li, X. Zang, Y. Cao, Y. He, P. Li, K. Wang, J. Wei, D. Wu, H. Zhu, RSC Advances 4 (2014) 36253-36256. https://doi.org/10.1039/C4RA05553E

[58] G. Radić, I. Šajnović, Ž. Petrović, M. Kraljić Roković, Croatica Chemica Acta 91(4) (2018) 481-490. https://doi.org/10.5562/cca3452

[59] S. T. Senthilkumar, R. K. Selvan, N. Ponpandian, J. S. Melo, Y. S. Lee, Journal of Materials Chemistry $A 1$ (2013) 7913-7919 https://doi.org/10.1039/C3TA10998D

[60] X. Liu, C. Men, X. Zhang, Q. Li, Liu, Small 12 (2016) 4973-4979 https://doi.org/10.1002/smll.201600841

(C)2021 by the authors; licensee IAPC, Zagreb, Croatia. This article is an open-access article distributed under the terms and conditions of the Creative Commons Attribution license (https://creativecommons.org/licenses/by/4.0/) 